\title{
Suggested Model (Related to the Student Portfolio) Used in Evaluation the Students in University Courses
}

\author{
Omar M. Mahasneh ${ }^{1} \&$ Odeh S. Murad ${ }^{2}$ \\ ${ }^{1}$ Assistant Professor of Curriculum and Instruction, AL-Balqa Applied University, AL-Shobak University \\ College, Maan, Jordan \\ ${ }^{2}$ Assistant Professor of Educational Psychology, AL-Balqa Applied University, AL-Shobak University College, \\ Maan, Jordan \\ Correspondence: Omar Musa Klaif Mahasneh, AL-Balqa Applied University, AL-Shobak University College, \\ Shobak (5) zip code (71911), Maan, Jordan. Tel: 96-277-206-0857. E-mail: Almahasneh2007@yahoo.com
}

Received: May 5, 2014 Accepted: May 28, 2014 Online Published: May 29, 2014

doi:10.5539/hes.v4n3p72 URL: http://dx.doi.org/10.5539/hes.v4n3p72

\begin{abstract}
This study aimed to develop a suggested model related to the student's portfolio used in evaluating the students in the university courses. After revising the theoretical literature and previous studies, two tools of the study have been constructed: Suggested model related to the student portfolio, and identifying the specifications towards using it in evaluation. After confirming the validity and reliability of the two tools of the study, they were applied to a sample of the study which consisted of (60) students from AlShobak university/Bachelor of Pre-Vocational Education, distributed equally into two groups (control group, and experimental group). To achieve the objectives of the study, two researchers evaluate the students in the course of "Foundations of Education" by using the suggested model of the student's portfolio to the experimental group, on the other hand, there was an evaluation of the control group students' educational acquirements in the traditional way, and to answer the questions of the study, both researchers used the averages and standard deviations, did the (T-Test), and did the analysis of unilateral and bilateral variance (ANOVA). The results of the study showed differences of statistical significance between evaluation of students through the suggested model of the student's portfolio and evaluation in the traditional way in favor of the suggested model. Results also showed positive trend of students towards their evaluation using the suggested model, in addition, results did not show differences statistically significant to students depending on both gender and academic level. The study recommended diversity in using the Authentic Assessment ways, and that would be through evaluation their outcomes, and doing more similar studies on methods and strategies of evaluation to university students.
\end{abstract}

Keywords: student's portfolio, university courses, the traditional assessment, authentic assessment

\section{Introduction}

\subsection{Background and Importance of the Study}

The great accelerated development in scientific knowledge, cultural openness, and the development of information and communication technology, in addition to multi-media access to knowledge, and the complexity of life and increasing in the number of skills that must be taught to the students, all of these created an urgent need to move from the methods of traditional evaluation to others taking into account the real development in teaching and learning strategies, especially if we know that a lot of skills can't be put right by using the paper and pencil exams, so traditional exams which students got used to centuries ago became a means of evaluation but not the only, and the role of students in determining the criteria by which they were put right increased, so the process of forming these criteria became participatory between teacher and student, therefore, evaluation was no longer the weapon the teacher used to sweeten or intimidation, on the contrary, it has become a way that directed students to achieve effective learning for productive knowledge which employed by students in their daily lives. Self-evaluation also became a means that enable students to revise themselves and introduce them feedback, which leads themselves for more learning and development and re-planning (Saud, 2008; Sidawi, 1997; Hart, 1994).

A revolution in Educational Evaluation and Syllogism has been noticed in recent years of this century, that is 
because evaluation has got new variable purposes. Educational evaluation is considered, on the part of decision makers, the main motivation that leads the staff of the educational institution to improve their performance, practicing and experience.

A change in the classroom is about to done in order to train teachers on new practices, and develop their knowledge and experience. In (1998) included in (Sandra, 1995), Alkhalili expected teachers to develop their skills and use Authentic Assessment strategies which aim to measure actual knowledge, and skills needed to be used by students efficiently in a realistic context.

The educational evaluation is considered an essential process in the teaching-learning process in all its dimensions and aspects, that is because transferring students from a subject into another in the course and from grade into another can be performed by evaluation only. For instance, success and failure, their intention to continue or stop study and choosing specialization, all of these decisions are based on the evaluation primarily.

Such status granted evaluation continuous attention and constant updating by educators, and perhaps the most recent contemporary term is that spread termed (Authentic Assessment) (Khalili, 1996; Kincker, 1997).

More attention to Authentic assessment results in increasing the motivation of students, stimulating them to independent learning, developing their skills and helping them employ their learning through activities performed by teachers and students through which they practice authentic assessment, this authentic assessment has a wide range of activities and practical offers which will provide real information on the progress of the students (Massoud, 2008).

The significance of evaluation comes from being a process associated with the process of planning and practicing of teaching, in order to discover weaknesses and treat them and enhance the strength norms. Learners differ from each other in the patterns of the learning process, the speed of the learning process, and in their abilities to connect the new knowledge with the old one. Therefore, teachers and university professors have to choose teaching and evaluation strategy that suits all students and takes into consideration individual differences, Authentic Assessment strategies followed by the teacher vary, some of them are:

1) Strategies based on performance.

2) Strategies based on observation.

3) Strategies based on communication.

4) Strategies based on self-examination, in addition to the evaluation strategy with a pen and paper, and many other methods and tools (Mahasneh, 2011).

Development in the process of evaluation of students, sharing them in the self-evaluation, identifying standards of evaluation, and the transition from traditional evaluation to authentic one will face many difficulties in the beginning, and that is because of depending students on specific patterns of evaluation. This requires good planning to introduce new evaluation programs, and sharing the teachers in the planning and implementation, and eliminating these recent developments in themselves, so that they form their clear convictions about the importance of the development intended to be implemented. On the other hand, the teacher has to focus on the indicators and evidence which the student has to show as evidence of the possession of learning outcomes required, and such evidence has to be documented in the student's portfolio (Student Portfolio) (Abu Ali, 2006).

\subsection{The Authentic Assessment Methods}

Zaitoon (2007) and Althoaibah (2006) mentioned that there are:

First: Method of the student diary (Response Journal): The Method of the student diary is considered one of the methods of evaluation and self-examination strategy through which student's thoughts, observations and interpretations; about what he had learned in the different searches; are documented, and it is an embodiment of the student's personal point of view, and his opinion on what he has learned whether he has done it well or not.

Second: Method of self-evaluation (Self-Assessment): Self-Assessment is a method of self-evaluation strategy away from the influence of others and their opinions, and without comparing himself with peers. It is a confession of self-abilities, inclinations, and the strength and weak points, so all of these make a mirror reflect what is going on in the mind of the student about the process of learning and teaching. So this strategy is considered - if used properly - a true reflection of the process of learning and teaching.

Third: Method of evaluation the student's portfolio (Portfolio): Portfolio is used by the teacher to evaluate the students' learning, and used by the student to evaluate his own learning. It is a sample of the student's best work selected precisely to show progress in the outcomes desired to be achieved during a specified period, while the 
portfolio is for one search.

Therefore, there is a portfolio for every subject, one for Arabic, another for English, a third for Science and the fourth of mathematics, and so on. Portfolio may contain examinations done by the student, or tools to authentic evaluation, or acts chosen by the student (student participation in a contest and receiving a prize or writing poem). Portfolio can be defined as the student's personal portfolio where all the students achievements are put in an order; according to the general framework of the subjects, or in accordance with the basic needs.

It also includes reports on personal projects and activities, research papers, creations reached, his memoirs about his practice process, and his memories. It also includes letters that indicate the communication between parent and teacher. The contents of this portfolio are considered the key for estimating the level of the student through factual achievements reached, where the student chooses some of the achieved work in this portfolio to be evaluated; teacher also chooses other works besides those chosen by the student for the purpose of assessment (Zaitoon, 2007).

Portfolio plays a fundamental role of learning since it is the documented statement of the growth of the pupil and their degree of progress in learning.

Fourth: The method of peer assessment (Peers-Assessment): A self-assessment represents one shape of peer assessment. This method can be classified under the authentication assessment strategies by notice, and evaluation based on communication and performance; through which the student evaluates a colleague on one of the activities.

Fifth: The evaluation method through written examinations (Writing Tests): This method can be classified under the authentication assessment strategies by pen and paper, questions in this exam is contemplative deductive.

Sixth: The evaluation method through maps concepts (Concept Mapping): Concept Mapping aims to reveal the relationships between a set of concepts through measuring them before and after learning for the student using observation, through which the teacher can judge on how the concepts of students are developing.

\subsection{The Purpose of the Study and the Research Questions}

The problem of the study is that the traditional assessment strategies are no longer commensurate with the modern educational developments, in relation to the transition from the behavioral philosophy, in which the teacher is considered the focus of teaching-learning process, and the student is the receiver of information, in addition to its focus on the mental side and non-rationed examinations to constructivism philosophy, in which the learner is considered the focus of teaching-learning process, the teacher is assisstant and mentor to student.

This philosophy focuses on the development of personality of the learner from all sides, and calls for the use of multiple assessment strategies that suit all students, and achieves comprehensive and balanced development of the individual. This is not limited to the use of authentic assessment strategies to real school students only, but employing these strategies must be transmitted into the high stages of university, This study attempts to answer the following research questions:

Q1: Are there statistically significant differences between the traditional assessment method of students and using the suggested model of the student's portfolio?

Q2: What are the students' attitudes towards the use of model student's portfolio in the evaluation of their achievement in university courses?

Q3: Does the students' attitudes towards the use of model student's portfolio in the evaluation of their achievements in university courses depend on the variable (gender, study level)?

\subsection{Objectives of the Study and Justification}

The study Aimed to:

1) Put a suggested model for the (student's portfolio) to be used in the evaluation of students in university courses.

2) Compare the student learning outcomes using the suggested model of the student's portfolio, and the traditional assessment method.

3) Identify the students' attitudes towards using the proposed model of the student's portfolio in the evaluation of their achievements in university courses.

4) Both researchers hope that the study opens new fields for subsequent studies and research in terms of the type of the object and its variables and outcomes associated with its samples. Researchers know that the Arab public 
library, and the library of Jordan are poor, especially for such a study, so the researchers felt that they should do this study.

\subsection{Determinants of the Study}

- Spatial Determinants: the study was limited to the students of the Shobak university/Bachelor's level of pre-vocational education.

- Temporal Determinants: the proposed model of the student's portfolio has been applied to the evaluation of students during the first semester of academic year 2013/2014, and a questionnaire has also been applied to identify students' attitudes towards the use of the proposed model for the student's portfolio in the evaluation at the end of the academic semester 2013/2014.

- The current study is limited to determine the contents of the proposed model of the student's portfolio, and to identify the students' attitudes toward their assessment using this proposed model in university courses.

- The study sample was limited to 60 students, so their results can be Looks ambitious to all statistical society and communities similar to it.

\subsection{The Study Terms}

Traditional Evaluation: it is a student assessment by pen and paper without using authentic assessment strategies and often measures mental aspects.

Authentic Assessment: it is the use of strategies that measures mental, emotional and psychological aspects such as assessment strategies based on performance, observation, communication, and self-examination.

The Student's Portfolio: it is one of the authentic assessment methods (introspection) through which the student saves all of their activities during semester within this portfolio.

Student Achievement: total marks of the student (the first and second exam and semester tasks and final exam) in the course of the foundations of education for the first semester of the academic year 2013/2014.

\subsection{Previous Studies}

After both researchers comprehended educational literature and previous studies; they didn't find any studies related to the subject matter directly, this search aimed to develop a proposed model for the student's portfolio to be used in the evaluation of students in university courses, some of the studies have been found on authentic assessment, The following is a summary of the most important of these studies: Bdour (2010) conducted a study aimed to find out the degree of mathematics teachers using the authentic assessment and its relationship with perfectly students' learning and their ability to solve math problems and attitudes in mathematics. The study sample consisted of (114) teachers and (566) male and female students from the eighth grade, the study used (5) measurement tools. The study found the presence of statistically significant difference attributable to the use of assessment strategies used by teachers, and the results of the study also showed that the average degree of mathematics teachers to evaluate their teaching in an authentic assessment classroom was (67.1\%).

Massoud (2008) conducted a study aimed to investigate the effect of the use of science teachers for the basic stage of assessment strategies on real understanding of the scientific concepts and their ability to think scientifically. The study sample consisted of 271 male and female students from the eighth grade, divided into eight people in four public schools belonging to the Second Directorate of Education Department in Amman (two schools were for males, and two were for females) in the first semester of the academic year 2007/2008, four divisions were chosen (two divisions were for males, and two divisions were for females) randomly to represent the students of the experimental group, and assessed these people using a authentic evaluation strategies, while the other four divisions were evaluated using traditional evaluation strategies The study found the presence of statistically significant difference attributable to the use of assessment strategies used and in favor of the experimental group in students' understanding of scientific concepts and in the development of scientific thinking for them. It was clear through the researcher who designed a test for understanding the scientific concepts and the use of scientific thinking scale to measure students' ability to practice scientific thinking skills. The study recommended using an authentic assessment strategies in the basic grades. It also recommended that the teacher evaluation stems from the actual outcomes achieved in order to evaluate the teaching process, and achieve alignment between teaching strategies and evaluation.

Aayasrh (2006) conducted a study aimed to investigate the effectiveness of the two evaluation strategies: student achievement bag and conceptual map for the students in the upper primary stage who study Physics in their understanding of the concepts of physics and their ability to think critically and their attitudes towards these two strategies. The study sample consisted of 110 female students from the ninth grade, divided into three divisions 
in a Directorate School in Amman. The study used the tests and critical thinking measure and measure of attitudes. The study didn't find any statistically significant difference in the outcomes of ninth grade students in physics attributed to the evaluation strategy (student achievement bag, and the conceptual map, and the traditional method) in the final outcome. And there wasn't any statistically significant difference in the performance of ninth grade students on a scale of critical thinking skills in physics attributed to the evaluation strategy inferred in depth (student achievement bag, and the conceptual map, and the traditional method). And the presence of a statistically significant difference in the performance of ninth grade students on a scale of critical thinking skills in physics attributed to the evaluation strategy (student achievement bag, the conceptual map, and the traditional way). The study recommended the need to adopt two authentic assessment strategies (student achievement bag, and the conceptual map) in the assessment of student learning, whether in school or in universities, which leads by using to improve students' learning process and methods of teacher education.

Abu Ali study (2006) aimed to find out the effectiveness of employing teaching methods based on the authentic assessment in developing the higher thinking skills among the tenth grade students in their attitudes towards science. The study sample consisted of 70 students from the tenth grade students, divided into two divisions, where one randomly designated to be the experimental group and appointed the other as a control one.

The study found a statistically significant difference between the average performance of students in the two groups of study - the experimental and control groups- on each of the measure of the higher thinking skills and attitudes towards science and in favor of the experimental group.

The study recommended hiring authentic assessment strategies by science teachers in their education, their experiences and connect knowledge to real-life situations, and take care of the development of thinking and attitudes towards science by providing opportunities for the student to practice science processes.

Kamonwan and Suwimon (2011) conducted a study aimed to know the effectiveness of the teachers use of the student's portfolio in the educational process in Thailand. The study results showed that the trend towards the use of teachers' portfolios of students was positive. McDonald (2012) conducted a study titled "student's portfolio evaluation" in the classroom in Taiwan and the results showed that the student's portfolio is considered a means for self-expression and developing personal individuals.

\section{The Study Methodology}

This study used the analysis of documents, and the descriptive approach to achieve its objectives by reference to getting back to previous educational literature. The proposed model for the student's portfolio was built to be used in the evaluation of students, and to collect data through a questionnaire designed by the two researchers to identify the students' attitudes towards the use of the proposed model for the student's portfolio in their evaluation in university courses.

\subsection{The Study Environment and Its Sample}

The study environment consisted of 345 male and female students from Shobak university, according to the Statistics Admission Division at the college, they were spread over two levels (intermediate diploma, bachelor's), one division of the bachelor was chosen - specialized in vocational education by intentional way-from students of the foundations of education course.

The Division consisted of 60 students divided randomly into two groups (the control group and the experimental group), and Table 1 shows the distribution of the study sample according to gender and academic level.

Table 1. Distribution of the study sample according to gender and academic level

\begin{tabular}{|c|c|c|c|c|c|c|c|c|}
\hline \multirow[t]{2}{*}{ Sample Type } & \multicolumn{2}{|c|}{ Gender } & \multirow[t]{2}{*}{ Total } & \multicolumn{4}{|c|}{ Academic Level } & \multirow[t]{2}{*}{ Total } \\
\hline & Males & Females & & $\begin{array}{l}\text { First } \\
\text { year }\end{array}$ & $\begin{array}{c}\text { Second } \\
\text { year }\end{array}$ & $\begin{array}{l}\text { Third } \\
\text { year }\end{array}$ & $\begin{array}{c}\text { Fourth } \\
\text { year }\end{array}$ & \\
\hline Control & 10 & 20 & 30 & 15 & 8 & 5 & 2 & 30 \\
\hline Experimental & 11 & 19 & 30 & 14 & 8 & 4 & 4 & 30 \\
\hline Total & 21 & 39 & 30 & 29 & 16 & 9 & 6 & 60 \\
\hline
\end{tabular}




\section{Equal Groups:}

Because both researchers were careful to control variables that may affect the operation of the experiment, and the accuracy of the outcome, taking into consideration that the sample of individuals were chosen from the area of one college, both researchers rewarded research groups of the following variables:

1). Randomness in the selection of two-group members of the study:

To achieve parity, the researcher selected random members of each of the control and experimental groups, and the effect of variable specialization has been isolated, and the sample of the study was students of vocational education specialization, all of them.

2). The average of high school:

The researchers got the average of study sample students from student records available in the unit of Admission in college. Using analysis of unilateral variance to ensure equal averages of students, the results showed no statistically significant differences, suggesting equal groups in this variable, and Table 2 shows the results of this analysis.

Table 2. The results of this analysis

\begin{tabular}{lccccc}
\hline & Sum of squares & df & Mean squares & F & Sig. \\
\hline Between groups & 43.02 & 2 & 21.5 & 1.30 & 0.290 \\
\hline Within groups & 1491.8 & 87 & 17.1 & & \\
\hline Total & 1534.9 & 89 & & & \\
\hline
\end{tabular}

\subsection{Study Tools}

The following tools were used in the study:

First, the proposed model of the student's portfolio:

After getting back to the theoretical literature about the contents of the student's portfolio, the proposed model was recorded on pages as the following:

1). Cover page including: (enterprise logo, department, college, the title of the portfolio, the student's name, university number, study year, level and specialization, e-mail address).

2). The second page of the student has demographic information including the following information: (student's name, age, place of residence, health status, method of learning, problems faced, work of the father, family income, number of family members).

3). The third page related to the course plan during the semester, including the following information: (description of course, the name of the course, information of instructor, office hours, times of lectures, lecture hall, course subjects, strategies and teaching methods, evaluation strategies and techniques, evaluation mechanism, references, homework, Instructions for students).

4). Page of homework, including the following information: (the name of the lecture, lecture date, homework title, homework evaluation).

5). Page of lecture evaluation including the following information: (evaluation criteria for the student and the teacher, marks allotment, the title of the lecture, lecture date, columns of evaluation and giving marks).

6). Page of summarizing the ideas of the lecture including the following information: (title of the lecture, lecture date, main ideas in the lecture.

7). Evaluation page of lecturer student, including the following information: (name of lecturer student, the name of the evaluation student, the criteria for evaluating the lecturer student, marks allotment, teacher evaluation, the subject of the lecture, the date of the lecture.

8). Criteria page for evaluating the students portfolio: including the criteria on which the student portfolio will be evaluated.

9). The progress page of learning: including what student writes about themselves in the lectures.

Second: The questionnaire (Likert type) of students' attitudes towards the use of the proposed model in 
evaluation :Two researchers prepared a questionnaire for measuring students' attitudes towards the use of the model, and this questionnaire consisted of (10) paragraphs.

\subsection{Validity of Tools}

Proposed model of the student's portfolio and the attitudes questionnaire have been showed to a number of arbitrators of a doctorate and master's degrees specialized in educational psychology, measurement and evaluation, and curriculum and teaching methods; some of the ideas have been modified, and scientific and linguistic errors have been corrected. As a result, (75\%) of the arbitrators in both instruments adopted what was acceptable for them,both tools were also applied for an exploratory sample consisting of (30) students from outside the members of the study sample, to ensure the safety and clarity of the language of the two tools.

\subsection{Reliability of Tools}

As regards steadily study tool, stability of the questionnaire as a whole has been calculated, using the stability of Cronbachs alpha (Alpha Cronbachs). The reliability coefficient was (0.85), and reliability coefficient of the questionnaire was calculated in a way of the test and re-test (Test-Retest) on the exploratory sample in two-week interval, and the reliability coefficient recorded $(0.83)$.

\subsection{Application Toolkit Study}

After verifying the validity and reliability of the study tools, both researchers did the following:

1). The proposed model of the student's portfolio was used to assess the experimental group in the course of the foundations of education, while the evaluation of the control group students was in the traditional manner (achievement tests), and the time of the application took one semester.

2). The students' attitudes questionnaire has been applied towards the use of the proposed model of the student's portfolio in evaluation the university students of the study sample at the end of the first semester of the academic year 2013/2014.

\subsection{Correction of Tool}

Answers were corrected on each paragraph of the questionnaire as follows: always (5 degrees), often (4 degrees), neutral (3 degrees), rarely (two degrees), never (one degree). Both researchers used the average of the weighted measure of attitudes, and use the following staging to measure the degree of direction: If the weighted average is (3.66 and above) then the attitudes are positive, and if the weighted average is between (2.33-3.65), the attitudes are moderate, and if the weighted average is between (1-2.32), the attitudes are negative.

\subsection{Statistical Treatment}

Both researchers entered data on a computer, statistical program of social sciences (SPSS) was used. Standard deviations, averages and stability coefficient of the study tool were calculated, ANOVA and bilateral cooperation has also been used to examine the effect of the study variables.

\section{Results and Discussion}

Q1: Are there statistically significant differences between evaluating students in the traditional way and using the proposed model of the student's portfolio? To answer this question, the study applied (T-Test) to examine the differences of final grades averages of students of the control and experimental groups, and Table 3 shows the results of the test.

Table 3. Test Results $(\mathrm{T})$ to examine the differences between the averages of final grades for each of the members of the two groups of control and experimental study

\begin{tabular}{lcccccc}
\hline Sample Type & NO. & Mean & Std. & T & df & Sig. \\
\hline Control & 30 & 82.4 & 3.6 & 11.8 & 58 & 0.000 \\
\hline Experimental & 30 & 94.2 & 3.6 & & & \\
\hline
\end{tabular}

Table 3. results suggest that the value (T) was (11.8), and the level of significance was (0.00) which is statistically significant at the level of significance $(\alpha \leq 0.05)$, suggesting the existence of moral and spiritual differences between the final scores of students course of the foundations of education between the control and experimental groups, and in favor of the experimental group, which the proposed model of the student's portfolio was used in the evaluation. This may explain the effectiveness of the proposed model in the evaluation, and that is because the 
participation of the student in the process of self- assessment and evaluation his colleagues, as well as the participation of the teacher evaluation, compared to the traditional way of evaluation by the teacher being the owner of the resolution, and the student scores depend on his performance in the achievement test which suggested by the teacher.

Q2: What are the students' attitudes towards the use of the proposed model of the student's portfolio in the evaluation of their achievement in university courses? To answer this question, the averages and standard deviations have been calculated for each paragraph of the scale, and the results showed that all members of the study sample of students' attitudes had positive attitudes towards the use of the student's portfolio during achievement evaluation in university courses by members of staff, and Table 4 shows that.

Table 4. Averages and standard deviations of the responses of the study sample on paragraphs to identify attitudes

\begin{tabular}{|c|c|c|c|c|}
\hline \multirow[t]{2}{*}{$\mathrm{N}$} & \multicolumn{4}{|c|}{$\begin{array}{c}\text { Attitudes towards the use of the student's portfolio during achievement evaluation in university courses by } \\
\text { members of staff }\end{array}$} \\
\hline & Paragraphs & Mean & $\begin{array}{l}\text { Standard } \\
\text { deviation }\end{array}$ & Attitudes \\
\hline 1 & $\begin{array}{l}\text { The student's portfolio helps me increase my self-confidence through } \\
\text { self-assessment and my teacher's assessment. }\end{array}$ & 4.67 & 1.04 & Positive \\
\hline 2 & $\begin{array}{l}\text { The student's portfolio increases my ability to perseverance and } \\
\text { offering and getting information, skills and attitudes. }\end{array}$ & 4.71 & .888 & Positive \\
\hline 3 & $\begin{array}{l}\text { The student's portfolio gives me access to the real (actual) level of } \\
\text { performance of my ability. }\end{array}$ & 4.69 & .989 & Positive \\
\hline 4 & $\begin{array}{l}\text { The student's portfolio develops my skills in leadership (classroom } \\
\text { management). }\end{array}$ & 4.51 & .713 & Positive \\
\hline 5 & $\begin{array}{l}\text { The student's portfolio makes me feel justice in my assessment, so I } \\
\text { do not focus on the test as the sole source in determining my score in } \\
\text { the course. }\end{array}$ & 4.41 & .804 & Positive \\
\hline 6 & $\begin{array}{l}\text { I feel relieved during the selection of educational activities that } \\
\text { should be placed in the business portfolio (the student's portfolio). }\end{array}$ & 4.35 & 1.49 & Positive \\
\hline 7 & $\begin{array}{l}\text { I feel relieved when setting up a special portfolio all my information } \\
\text { were written. }\end{array}$ & 4.58 & 1.34 & Positive \\
\hline 8 & $\begin{array}{l}\text { I encourage the use of the student's portfolio in the evaluation of the } \\
\text { students performance in university courses. }\end{array}$ & 4.51 & .660 & Positive \\
\hline 9 & The student's portfolio develops my ability to create and innovate. & 4.78 & .594 & Positive \\
\hline 10 & The student's portfolio makes me feel that I am the focus of teacher. & 4.46 & .785 & Positive \\
\hline
\end{tabular}

We note from the above table that all the members' attitudes of the study were positive towards the use of the student's portfolio during their evaluation in university courses. The average of the total instrument is (4.54) and both researchers see that the student's portfolio helps to assess students in all of mental, physical, emotional aspects, and this has been confirmed by studies of (Bdour, 2010; Massoud, 2008; Aayasrh, 2006; Abu Ali, 2006), which had positive results and one of them is the use of authentic assessment strategies in evaluation the students.

Q3: Does the students' attitudes towards the use of model student's portfolio differ in the evaluation of their achievement in university courses depending on the variables (gender, study level)? To answer this question, the study conducted analysis of bilateral variance to determine the effect of binary variables (gender, study level) on students' attitudes towards the use of the proposed model for the student's portfolio in the evaluation of student achievement in university courses, and Table 5 shows the results of this analysis. 
Table 5. The results of analysis of univariate variance of the effect of variables (gender, study level) on students' attitudes

\begin{tabular}{cccccc}
\hline Source & $\begin{array}{l}\text { Sum of } \\
\text { square }\end{array}$ & df & Mean square & F & Sig. \\
\hline Gender & 510.57 & 1 & 510.57 & 2.31 & 0.134 \\
\hline Study Level & 309.50 & 3 & 103.20 & 0.47 & 0.706 \\
\hline Study Level-gender & 435.20 & 3 & 145.10 & 0.65 & 0.582 \\
\hline Error & 11475.70 & 52 & 220.70 & & \\
\hline Total & 3389230 & 60 & & & \\
\hline
\end{tabular}

It is obvious from the results shown in the table (5) that the value of $(\mathrm{F})$ of each of the study variables (gender, study level) amounted respectively $(0.47,2.31)$,which isn't statistically significant at the level of significance $(\alpha \leq 0.05)$, and this confirms the absence of the impact of each of the student's gender or level of academic trend towards the use of the proposed model of the student's portfolio in the evaluation of students in university courses.

This may be attributed to the strong desire of the students in participation in the evaluation process, and the replacement of their role as participants in the educational process; instead of their previous roles of information receivers only, and this confirms the students' motivation to learn and their desire to participate in the teaching-learning process in all its aspects.

\section{Recommendations}

In light of these findings:

1). both researchers recommended to all the staff members at public, local and private and Arab universities to generalize the need to use the student's portfolio model at university levels because of its impact on student achievement and student motivation to learn and search for information.

2). Both researchers also suggest to do further research on the evaluation of different strategies, including the use of the student's portfolio in the evaluation of university students and its relationship to other new variables.

\section{Acknowledgements}

I would like to thank Assistant Professor of Educational Psychology (Odeh Murad) at AL-Balqa Applied University, AL-Shobak University College.

\section{References}

Aayasrh, A. (2006). The Effectiveness of strategies Takiametin: Bag student achievement and map conceptual stage students higher basic in their understanding of the concepts of physics and their ability to think critically and their attitudes towards these two strategies (Unpublished doctoral dissertation). University of Jordan, Amman, Jordan.

Abu Ali, M. (2006). The Effectiveness of employing teaching methods based on the real Evaluation in the development of higher-order thinking skills at the tenth grade students in their attitudes towards science (Unpublished doctoral dissertation). University of Jordan, Amman, Jordan. Retrieved from http://www.ju.edu.jo/10.17899897655467

Althoaabh, A. (2006). "The real evaluation", the Ministry of Education in the Hashemite Kingdom of Jordan. Message Guru, 2006(4), Amman, Jordan. Retrieved from http://www.ju.edu.jo/10.109389764

Bdour, A. (2010). The degree of mathematics teachers to evaluate their relationship to the real and perfectly students'learning and their ability to solve math problems and attitudes towards mathematics (Unpublished doctoral dissertation). University of Jordan, Amman, Jordan.

Hart, D. (1994). Authentic assessment: A handbook for Educators. Menlo Park, California. Reading, Massachusetts. New York, Don Mills, Ontario. Workingham, England. Amsterdam. Bonn. Sydney. Singapore. Tokyo. Madrid. San Juan. Paris. Seoul. Milan. Mexico City. Taipei: Addison-Wesley Publishing Company. Retrieved from http://www.ju.edu.jo/10.10938896

Kamonwan, T., \& Suwimon, W. (2011). Teacher Attitude and needs Assessment Concerning the Use of Student portfolio. Mokslos Tripsnial. Retrieved from http://www.ju.edu.jo/10.10.789 
Khalili, K. (1996). The teaching of science in general education. Dar Pen Publishing and Distribution, Dubai, United Arab Emirates.

Khalili, K. (1998). The real evaluation in education. Journal of the Qatari National Committee for Education, Culture and Science. Bahrain.

Khayat, N. (1996). Evaluation portfolios using student work the foundation of education to him. Paper presented at the Educational Conference annual atheist ten on the evaluation system of education in basic education, which was held in Manama during 16 to 18 September 1996, organized by the Ministry of Education in Bahrain.

Kincker, C. (1997). An overview of authentic assessment, Weaving Authentic Assessment into the Tapestry of Learning. Comprehensive Regional Assistance Center Consortium-Region VI, 2(1). Retrieved from http://www.ju.edu.jo/10.10786965

Mahasneh, O. (2010). Professional education curricula and teaching strategies and evaluation. House of World Culture Publishing and Distribution, Amman, Jordan.

Massoud, M. (2008). The impact of the use of science teachers for the basic stage of assessment strategies in a real understanding of their students to scientific concepts and their ability to think scientifically (Unpublished doctoral dissertation). University of Jordan, Amman, Jordan. Retrieved from http://www.ju.edu.jo/10.1093

McDonald, B. (2012) Portfolio assessment: Direct from the classroom, Journal Articles; Reports-Research. Trinidad and Tobago. Retrieved from http://www.ju.edu.jo/10.109378995

Sidawi, A. (1996). Towards Educational Evaluation real. Paper presented at the Annual Conference of Educational atheist century and organized by the Ministry of Education in the State of Bahrain and held in Manama, during the period September 16 to 18, 1996 AD. Retrieved from http://www.ju.edu.jo/10.1896

Zaiton, A. (2007). Constructivist theory in the teaching of science. Sunrise House for Publishing and Distribution, Amman, Jordan.

\section{Copyrights}

Copyright for this article is retained by the author(s), with first publication rights granted to the journal.

This is an open-access article distributed under the terms and conditions of the Creative Commons Attribution license (http://creativecommons.org/licenses/by/3.0/). 